\title{
ZFAS
}

\section{Im Osten viel Neues. Deutsche Ostpolitik aus polnischer Perspektive}

\author{
Adam Krzemiński
}

Online publiziert: 23. Dezember 2014

(C) Die Autor(en) 2014. Dieser Artikel ist auf Springerlink.com mit Open Access verfügbar

Zusammenfassung Seit dem Euromajdan rückte die Ukraine ins Zentrum nicht nur der deutschen oder polnischen Ostpolitik, sondern der gesamten EU. In dieser Situation wurden die alten Dilemmata der 80er Jahre wieder erkennbar: Wie soll den Emanzipationsbestrebungen in Russlands „nahem Ausland“ und der Bereitschaft dieser lädierten Großmacht, sich auch mit Gewalt dort durchzusetzen, begegnet werden? Dieser Beitrag diskutiert die deutsche und gesamteuropäische Reaktion auf diese Krise aus polnischer Perspektive. In den Protesten sah man in Polen eine zeitverschobene Fortsetzung jener ostmitteleuropäischen Revolution, die 1989 letztlich zum Kollaps des Kommunismus und der Sowjetunion führte.

Schlüsselwörter Ostpolitik $\cdot$ Deutschland $\cdot$ Polen $\cdot$ Ukraine $\cdot$ Russland

\section{Nothing Quiet on the Eastern Front. German Ostpolitik from a Polish Perspective}

\begin{abstract}
The Euromaidan protests put the Ukraine on center stage not only for German or Polish Eastern policy, but for the EU as a whole. In this situation an old dilemma of the 1980's became apparent: how to deal with an emancipatory movement in Russia's sphere of influence and the readiness of this fading great power to weigh the movement down by force? This article discusses the German and European reaction to this crisis from a Polish perspective. In Poland the Euromaidan protests were interpreted as a time-shifted continuation of the Polish emancipatory movement of the 1980's which eventually lead to the collapse of communism in Eastern Central Europe.
\end{abstract}

\footnotetext{
A. Krzemiński $(\bowtie)$

UL. Koszykowa $35 \mathrm{~m} 2$, 00-553 Warszawa, Polen

E-Mail: krzem@gmx.net
} 
Keywords Ostpolitik $\cdot$ Germany $\cdot$ Poland $\cdot$ Ukraine $\cdot$ Russia

100 Jahre nach Ausbruch des Ersten und 75 Jahre nach dem des Zweiten Weltkrieges, 25 Jahre nach der Revolution in Ostmitteleuropa und 10 Jahre nach der Osterweiterung der EU wird ein polnischer Ministerpräsident - nicht zuletzt dank des Zuspruchs der deutschen Bundeskanzlerin - Vorsitzender des Europäischen Rates, also Präsident Europas. Und zwar ausgerechnet während eines unerklärten russisch-ukrainischen Krieges, der wegen des Drangs der Ukrainer in die EU vom Zaun gebrochen wurde. Nun spielt sich die deutsche Ostpolitik nicht erst seit Polens EU-Beitritt weitgehend in einem deutsch-russisch-polnischen Dreieck ab, denn das gab es virtuell bereits im 19. Jahrhundert, obwohl seit den Teilungen Polens durch Russland, Preußen und Österreich Ende des 18. Jahrhunderts auf der europäischen Karte gar kein polnischer Staat existierte.

Nach dem Wiener Kongress 1815 war die Verhinderung einer Wiedergeburt Polens eines der wichtigsten Bindeglieder der konservativen „Heiligen Allianz“ der Teilungsmächte. Während des „Völkerfrühlings“ 1848 sahen manche - darunter auch Karl Marx - im freiheitlichen Polen ein Bollwerk gegen die ,halbasiatische Despotie" des russischen Zaren, während den Nationalliberalen der Schutz der polnischen Teile Preußens vor polnischen Insurgenten wichtiger war. Der polnische Leim erwies sich als stark genug, um Bismarck 1871 die russische Akzeptanz für die Gründung des Deutschen Kaiserreiches zu sichern, aber zu schwach, um dann die „Dreikaiserallianz" aufrechtzuerhalten.

Bei Ausbruch des Ersten Weltkrieges verwandelte sich der Leim in einen Sprengstoff, mit dem St. Petersburg, Berlin und Wien Breschen beim Gegner aufreißen wollten. Bereits im August 1914 legten alle drei einstigen Teilungsmächte die polnische Karte auf den Tisch. Damit wollten sie die Polen von der Gegenseite zu sich herüberziehen. Doch erst ihr gleichzeitiger Kollaps 1918 ermöglichte tatsächlich die Gründung eines souveränen polnischen Staates, der allerdings sowohl in Berlin als auch in Moskau als „Saisonstaat“ und „Missgeburt von Versailles“ betrachtet wurde. Die bereits 1920 während des polnisch-sowjetischen Krieges begonnene Zusammenarbeit der Reichswehr mit der Roten Armee hatte eine klare antipolnische Spitze, ebenso wie der Vertrag von Rapallo 1922.

Da die Westmächte der Machtübernahme Hitlers untätig zugesehen hatten, versuchte Polen 1934 sich durch Nichtangriffserklärungen mit beiden großen Nachbarn abzusichern. So lehnte Warschau 1938/1939 auch das ,großzügige Angebot“ Hitlers ab, für die Grenzkorrekturen im Westen auf Kosten der Sowjetunion im Osten entschädigt zu werden, und setzte auf die Allianz mit Frankreich und England. Der Hitler-Stalin-Pakt vom 23. August 1939 mit dem ,geheimen Zusatzprotokoll“" bildete dann den Auftakt zum gemeinsamen Angriff der beiden auf Polen. Doch auch diesmal erwies sich der ,,polnische Leim“ als zu schwach, um einen imperialen Interessengegensatz der totalitären Nachbarn zu kitten und den deutsch-sowjetischen Krieg zu verhindern.

Auch nach 1945 verschwand die deutsch-polnisch-russische Dreiecksgeschichte nicht. Sie erhielt aber durch die Spaltung Deutschlands, die sowjetische Hegemonie über Ostmitteleuropa und die Ablehnung der Oder-Neiße-Grenze durch die Bun- 
desrepublik einen anderen Charakter. Sowohl für Bonn als auch für Ost-Berlin war die Präsenz der Roten Armee in Deutschland entscheidend, daher wurde Moskau als das wahre Machtzentrum betrachtet. Auf die aufgezwungene Anerkennung der polnischen Westgrenze durch die DDR 1950 folgte keineswegs eine aufgezwungene „Freundschaft unter Brudervölkern“.

In Bonn wiederum sprach Konrad Adenauer zwar von einer angestrebten Versöhnung mit Polen, dem realen polnischen Staat im sowjetischen Machtbereich entzog man jedoch die Legitimität und damit auch die Anerkennung der polnischen Westgrenze. Zugleich wurde in der westdeutschen Öffentlichkeit die deutsche Schuld an der Zerschlagung Vorkriegspolens sowie der Besatzungspolitik von den Nachkriegsvertreibungen der Deutschen in den Schatten gestellt. Nach Stalins Tod suchte man den Dialog mit Moskau, um die deutschen Kriegsgefangenen freizubekommen, nicht aber mit Warschau. Und Moskau selbst war Polen gegenüber kein „,wohlwollender Hegemon“ - es machte die Anerkennung der Oder-Neiße-Grenze nicht etwa zu einer Bedingung für die Aufnahme diplomatischer Beziehungen mit Bonn, da die Offenhaltung der Grenzfrage ja auch in seinem Interesse lag, band sie doch Volkspolen fest an die UdSSR als einzigen realen Garanten der Grenze. Und umgekehrt erweiterte jede vertragliche Entspannung in Mitteleuropa die politischen Freiräume der VR Polen. Das war der Hintergrund des „Rapacki-Plans“ von 1957, in dem der damalige polnische Außenminister vorschlug, die Bundesrepublik, die DDR, die Tschechoslowakei und Polen zur atomwaffenfreien Zone zu erklären. Adenauer lehnte den Plan ab. Er vermutete dahinter einen sowjetischen Versuch, die Bundesrepublik der NATO zu entfremden. Aus einer ähnlichen Überlegung heraus wird Polen nach seinem NATO-Beitritt 1999 darauf drängen, NATO-Soldaten quasi als „Stolperdraht“ für den Fall einer russischen Provokation in Polen zu stationieren.

Der Mauerbau in Berlin 1961 veränderte die westdeutsche Perspektive und auch die Wahrnehmung Polens. Der Neuen Ostpolitik der SPD lag wohl die Erkenntnis zugrunde, dass die Berliner Mauer und die Oder-Neiße-Grenze den ostpolitischen Solarplexus verbinden. Das Ziel des ,Wandels durch Annäherung“ waren die Durchlöcherung der Mauer und „menschliche Erleichterungen“ im Verkehr zwischen den beiden deutschen Staaten. Der Weg dahin mochte mehr über Moskau als über Ostberlin führen, aber der Rubikon, den man dabei überschreiten musste, hieß Oder-Neiße-Grenze.

Die Akzeptanz der sowjetischen Hackordnung bei der Grenzanerkennung - zuerst ihre Bestätigung im Moskauer Vertrag und erst danach in bilateralen deutsch-polnischen - weckte Unmut in Warschau. Auch Washington war misstrauisch gegenüber Bonn, zumal der sowjetische Parteichef, Leonid Breschnjew, den Bundeskanzler unumwunden mit den Vorzügen einer neuen Rapallo-Politik becircte. Nicht allein der Warschau-Besuch Brandts glich einem ,psychischen Ausnahmezustand“, wie es ein Brandt-Biograf formulierte (Noack 2013), sondern die Verortung Polens im deutschen politischen Bewusstsein überhaupt. Bezeichnend war hierfür die heftige interne Debatte in der christdemokratischen Fraktion 1972 vor der Ratifizierung der Ostverträge. Als Johann Baptist Gradl die lästige, aber unausweichliche Anerkennung der polnischen Grenze als das Herzstück des ganzen Pakets nur mit Moskau erledigen wollte, entgegnete ihm Richard von Weizsäcker, dass für ihn die Priorität gerade bei dem Vertrag mit Warschau liege (Hofmann 2011a). 
Die Strategie der „neuen deutschen Ostpolitik“ der sozialliberalen Koalition der 70er Jahre beruhte auf der Ost-West-Entspannung, die zweigleisig war. Einerseits bestätigte die KSZE-Konferenz 1975 die sowjetische Herrschaft in Ostmitteleuropa. Andererseits ermutigte sie durch den „Korb 3“ eine Demokratisierung von unten durch Oppositionsgruppen und Bürgerbewegungen. Mit der Eruption der „Solidarnośćc in Polen gerieten 1980 beide Ziele der Entspannungspolitik - strategische Stabilität des Systems und politische Freiheit für die Menschen - in einen inneren Widerspruch: den Status quo zu wahren und zugleich aushebeln zu lassen.

Als im Oktober 1981 die Solidarność-Sprecher Bronisław Geremek und Tadeusz Mazowiecki in Brüssel um wirtschaftliche Unterstützung für das krisengeschüttelte Polen warben, was die Solidarność gegenüber der Regierung in Warschau politisch aufgewertet hätte, wurden sie hinauskomplimentiert: Man bewundere den Mut der Solidarność, die Welt aber sei gespalten und niemand könne das ändern (Hofmann 2011b, S. 292-293). Der Kriegszustand in Polen - die gewaltsame Unterdrückung der Solidarność, auch um eine sowjetischen Intervention zu vermeiden - offenbarte diesen Widerspruch der Entspannungspolitik. Es waren nicht nur deutsche Sozialdemokraten, die Verständnis für General Jaruzelski hatten, aber sie waren eben an der Regierung. Bundeskanzler Helmut Schmidt - gerade zu Besuch in der DDR zeigte sich ,,bestürzt, dass dies nun notwendig war“. Und die Worte des Strategen der Ostpolitik Egon Bahr, der Weltfriede sei wichtiger als Polen (Preuße 2014, S. 207), bewegten Władysław Bartoszewski, den späteren Außenminister des nunmehr freien Polen, in seiner Friedenspreisrede 1983 zu einer öffentlichen Polemik. Zehn Jahre später räumte Egon Bahr sein Fehlurteil ein, denn er glaubte ja, dass ein kommunistisch regiertes Land sich nur von oben verändern könne und übersah dabei die Sonderrolle Polens im Ostblock (Bahr 1996).

Der deutsch-polnische Solarplexus der Ostpolitik war der Beginn jener deutschpolnischen Interessengemeinschaft, die der polnische Außenminister der Mazowiecki-Regierung Prof. Krzysztof Skubiszewski im Februar 1990 formulierte. Nach dem grandiosen Wahlsieg der ,Solidarność“ am 4. Juni 1989 und der Öffnung der Berliner Mauer am 9. November bestand sie darin, dass Polen die deutsche Vereinigung und Deutschland die Heranführung Polens an die euroatlantischen Strukturen unterstützen würden. Polen hätte die Vereinigung Deutschlands zwar nicht verhindern, sie aber durchaus stören können - in der Hoffnung etwa auf Widerstand und einen Umsturz in Moskau, wie er 1991 auch tatsächlich versucht wurde. Das wiederum hätte die Wiedervereinigung wahrscheinlich nicht verhindert, aber die gegenseitigen Beziehungen nachhaltig vergiftet. Kein derartiger Versuch ist in Warschau unternommen worden. Im Gegenteil: Abgeordnete der „Solidarność“ wie Bronisław Geremek und Adam Michnik erklärten bereits im August 1989 im Sejm, die Deutschen hätten das Recht, sich zu vereinigen. Was im „Wunderjahr“ der ostmitteleuropäischen Revolution als eine momentane Interessenkoinzidenz erscheinen konnte, war jedoch eine gewaltige tektonische Verschiebung in der europäischen Zeitgeschichte. Heinrich August Winkler bringt sie im Vorwort zur polnischen Ausgabe seines „Langen Weges nach Westen“ auf den Punkt: 1989 konnte die deutsche Frage „zur gleichen Zeit und in Verbindung mit einem anderen Jahrhundertproblem gelöst werden - mit der polnischen Frage. Und das verleitet sowohl zu einem historischen Rückblick als auch zu einem Zukunftsentwurf.“ (Winkler 2007) 
Auf den historischen Kontext hat auch Helmut Kohl immer wieder hingewiesen, indem er seine Gesprächspartner - darunter Timothy Garton Ash (Frei 2012), aber auch den polnischen Botschafter in Bonn Janusz Reiter - darauf aufmerksam machte, dass er als erster Kanzler des vereinten Deutschlands direkter Nachfolger Adolf Hitlers im Amt sei und dass Welten zwischen den beiden Deutschlands lägen. Diese Vorgeschichte der deutschen Ostpolitik muss man sich insofern immer wieder vergegenwärtigen, als ihre langen Linien immer wieder kenntlich werden, trotz der nach 1989 veränderten politischen Geographie Europas.

Einen Zukunftsentwurf für Europa, von dem Heinrich August Winkler sprach, wagte wiederum zwei Jahrzehnte später - nachdem Polen ebenfalls im Westen als NATO- und EU-Mitglied angekommen war - der polnische Außenminister Radosław Sikorski. Seine Rede, die er am 28. Dezember 2011 in Berlin vor der DGAP hielt, überraschte, wenn nicht gleich die europäische, so doch die deutsche und die polnische Öffentlichkeit. Die größte Gefahr für Polens Sicherheit und Wohlstand sah Sikorski

nicht im Terrorismus, nicht in den Taliban und bestimmt nicht in deutschen Panzern. Noch nicht einmal in den russischen Raketen, die Präsident Medwedjew gerade an der Grenze zur EU aufzustellen gedroht hat. Die größte Bedrohung für Polens Sicherheit und Wohlstand wäre der Kollaps der Eurozone. Und ich verlange von Deutschland, dass es - um seiner selbst und um unseretwillen - dieser Eurozone dabei hilft, zu überleben und zu florieren. Sie wissen sehr wohl, dass niemand sonst das tun kann. Ich bin vermutlich der erste polnische Außenminister in der Geschichte, der das sagt, aber: Ich fürchte die deutsche Macht weniger als ich die deutsche Untätigkeit zu fürchten beginne. Sie sind Europas unverzichtbare Nation geworden. Sie dürfen bei der Führung nicht versagen. Nicht dominieren, sondern bei den Reformen die Führung übernehmen. (Sikorski 2011)

Dass ausgerechnet ein Pole von Deutschland mehr Führung in Europa forderte, war historisch und psychologisch recht ungewöhnlich. Die nationalkonservative Opposition war entsetzt. Der Vorsitzende der Partei „Recht und Gerechtigkeit“, Jarosław Kaczyński, der das von Donald Tusk regierte Polen 2010 „ein deutsch-russisches Kondominium“ nannte, kündigte eine Klage gegen Sikorski vor dem Staatstribunal an, weil der Außenminister eine „untergeordnete Position Polens“ akzeptiere und die - in der Verfassung festgeschriebene - Souveränität verneine. Seine Zukunftsvorstellung von der EU bedeute für Polen eine Rückkehr zur halbkolonialen Lage wie vor 1989. Obwohl Sikorski am 12 Januar 2012 das Vertrauensvotum im Parlament gewann, ebbte die Kritik an ihm nicht ab.

Die große deutsch-polnische Interessengemeinschaft nach 1989 hatte in der Ostpolitik der beiden Länder verschiedene Phasen. Sowohl das vereinte Deutschland als auch das freie Polen waren nach dem Zerfall der Sowjetunion an der Stabilisierung des postsowjetischen Staaten interessiert, aber mit unterschiedlichen Akzenten. Während Polen sich um die Aufnahme in die EU und NATO bemühte und im Umgang mit den postsowjetischen Staaten eine Symmetrie in seinen Beziehungen mit Moskau auf der einen Seite und mit Kiew, Minsk oder den baltischen Staaten auf der anderen zu seiner Grundlinie erhob, galt in Bonn, wenn schon nicht mehr das Prinzip 
„Russia first“, dann auf jeden Fall „,not without Russia“. Das vereinte Deutschland war Anwalt nicht nur der Aufnahme Polens in die NATO, sondern auch einer Anbindung Russlands an die euroatlantischen Strukturen durch den NATO-Russland-Rat und das Partnerschafts- und Kooperationsabkommen EU-Russland. Die Aufwertung Russlands - auch durch seine Aufnahme in die G7-Gruppe - sollte die russische Verärgerung über die Osterweiterung besänftigen, während die GUS-Staaten stillschweigend zur russischen Einflusszone zugerechnet wurden. Trotz der unterschiedlichen Perspektiven der „russophoben“ Polen und der „russophilen“ Deutschen - wie es Hennig Tewes formulierte (nach: Węsierski 2014) - gab es in den 90er Jahren keine gravierenden ostpolitischen Gegensätze zwischen Deutschland und Polen.

Sie tauchten erst mit dem Irak-Krieg 2003 auf. Die Ostmitteleuropäer unterstützten Bushs „Koalition der Willigen“ nicht nur, weil sie beweisen wollten, dass sie zuverlässige NATO-Mitglieder sind, sondern weil sie angesichts ihrer eigenen Geschichte den Sturz einer Diktatur für rechtens betrachteten. Das deutsche Nein und das polnische Ja wurde in Amerika zu einer Spaltung in das ,alte“ und das „,neue Europa“ stilisiert und hatte bald auch ostpolitische Folgen, als der neue russische Präsident Wladimir Putin dem ,alten Europa“ seine Hand reichte und mit der Gemeinsamen Erklärung mit Berlin und Paris vom März 2003 ein Gegengewicht in Europa zur amerikanischen Politik zu schaffen suchte. Als noch der französische Staatspräsident Jacques Chirac den Ostmitteleuropäern unwirsch beschied, sie hätten in der IrakFrage die ,großartige Gelegenheit verpasst, den Mund zu halten“ (zit. nach: Jäger und Dylla 2008, S. 47), da die Weltpolitik in Europa den Großen und Wichtigen obliegt, entstand der Eindruck, die Ostmitteleuropäer setzten auf die Angelsachsen, während Deutschland, Frankreich und Russland eine Art „Kontinentalblock“ anstrebten.

Polen - seit 1999 NATO-Mitglied und damals kurz vor dem EU-Beitritt - befand sich in einem zermürbenden Wahlkampf, und die aufstrebenden Nationalkonservativen, ohnehin Deutschland gegenüber distanziert, sahen sich in ihren Verdächtigungen bestätigt, dass Berlin in der westlichen Gemeinschaft ein unsicherer Kantonist sei und die deutsch-polnischen Beziehungen abgekühlt werden müssten, da angesichts der deutschen hegemonialen Ansprüche in Europa Deutschland und Polen nicht mehr eine Interessen-, sondern nur noch eine Streitgemeinschaft verbinde (Cichocki 2004). Und nach dem Doppelsieg der Nationalkonservativen aus der Partei „Recht und Gerechtigkeit“ der Gebrüder Kaczyński in den Parlaments- und in den Präsidentschaftswahlen 2005 waren in der Öffentlichkeit wieder deutsch-polnische Streitthemen vorherrschend: das vom Bund der Vertriebenen avisierte Zentrum gegen Vertreibungen; die „Quadratwurzel-Debatte“ - ein erfolgloser Versuch Warschaus 2007, die strukturelle Übergewichtung Deutschlands im Europäischen Rat zu konterkarieren - und insbesondere die deutsch-russische Ostsee-Gaspipeline, die der damalige polnische Verteidigungsminister - derselbe Radosław Sikorski, vor seinem Parteiwechsel - 2006 in Brüssel mit dem Ribbentrop-Molotow-Pakt verglich.

Sikorskis Reiterattacke konnte man auch als Antwort auf die vollmundige Belobigung des russischen Präsidenten als ,lupenreinen Demokraten“ (Hamburger Abendblatt 2004, 23. Nov.) durch den Bundeskanzler Schröder verstehen. Dieses geflügelte Wort wurde ausgerechnet in dem Moment bei einer Talk-Show in den Medienwind gesprochen, als in Kiew nach gefälschten Präsidentenwahlen Massenproteste ausbrachen, während Putin auf den Wahlfälscher Wiktor Janukowytsch setzte. Die zerstrit- 
tenen Parteien baten den polnischen Staatspräsidenten um Vermittlung. Aleksander Kwaśniewski kannte beide Kontrahenten, sicherte sich aber das Mandat der EU. Er holte den litauischen Staatspräsidenten Valdas Adamkus und „Mr. Europe“ Javier Solana hinzu und bat Paris und Berlin, ihrerseits auf Moskau einzuwirken. Es sei sein schwierigstes Gespräch mit Putin gewesen, bekannte Schröder später (Roxburgh 2012). Trotz des deutsch-polnischen Zerwürfnisses 2003 um den Irak-Krieg und der Irritation des „Briefes der Acht“ konnte man während der ukrainischen Revolution in Orange Ansätze einer gemeinsamen Ostpolitik der EU erkennen. Sie hielt aber nicht lange.

Denn der kurz vor der Bundestagswahl 2005 unterzeichnete Vertrag über den Bau einer Ostsee-Gaspipeline zwischen Russland und Deutschland wurde - übrigens nicht nur in Polen - als ein Indiz für die Rückkehr zur Priorität des Nationalen in der deutschen Russlandpolitik gewertet, die über die Köpfe der Ostmitteleuropäer und zu ihrem Schaden abgespult wird. Sie ließ eine Abneigung gegen die Entwicklung einer gemeinsamen Energiepolitik der EU erkennen, während in Polen im Zentrum der Beitrittsdebatten neben der erhofften gemeinsamen Sicherheits- und Außenpolitik der EU eben auch eine gemeinsame Energiepolitik stand - quasi als Erweiterung und Vertiefung der westeuropäischen Montanunion der 50er Jahre. Ein Schuss Geschichtsneurose schwang da in Sikorskis Ausbruch mit. Die deutschen Medien fanden ihn zwar aberwitzig, doch auch irgendwie begründet. Er spiegele - kommentierte die Berliner Zeitung -

Vorurteile, Argwohn und existenzielle Ängste, die in Polen weit verbreitet sind. Nahrung erhielten sie durch die Art und Weise, in der Bundeskanzler Gerhard Schröder und der russische Präsident Wladimir Putin das Projekt der Ostsee-Pipeline vorangetrieben hatten: Berlin hielt jegliche Konsultation mit dem betroffenen Nachbarn und Bündnispartner in NATO und EU für unnötig. Die Vorstellung mag uns absurd erscheinen, dass Polen von Erdgaslieferungen abgeschnitten werden soll. Aber einen gewaltigen wirtschaftlichen Nachteil wird das Land durch die Ostsee-Pipeline tatsächlich haben: Nach ihrer Fertigstellung gehen Transitgebühren für die Durchleitung des Rohstoffs nach Westeuropa verloren. Warschau will deshalb erreichen, dass die Pipeline nicht gebaut wird. Sikorskis Vergleich scheint darauf hinzudeuten, dass den polnischen Politikern dafür so ziemlich jedes Mittel recht ist. (Herold 2006)

Nicht nur die Pipeline schürte Dissens zwischen Berlin und Warschau, sondern auch Bemühungen der Ostmitteleuropäer, in der NATO dieselben Sicherheitsstandards zu bekommen, wie sie die Westeuropäer genießen, und nicht mit ,papiernen Garantien“ - wie schon mehrmals in der Geschichte - abgespeist zu werden. So wie die Bundesrepublik vor 1989 unter dem amerikanischen Schutzschild eine stabile Demokratie aufbauen konnte, brauchen auch die Ostmitteleuropäer eine defensive Präsenz der Allianz, die sie vor Versuchungen einer renovatio imperii aus dem Osten schützen würde. Während Warschau und Prag sich daher am amerikanischen Raketenabwehrschirm beteiligen wollten, wurde in Deutschland gerne die russische Kritik an dem Vorhaben aufgegriffen.

Die Regierung der Großen Koalition modifizierte den ostpolitischen Stil des Vorgängers, hielt aber an seinen Grundlinien fest, was insofern nicht verwunderlich war, als mit Frank-Walter Steinmeier ein enger Mitarbeiter Gerhard Schröders neuer Bun- 
desaußenminister wurde. Die SPD hatte in der Koalition deutlich mehr Gewicht als die Grünen unter Kanzler Schröder. Und Steinmeier zeigte, dass er der Ostpolitik seinen eigenen Schriftzug geben will. Auf dem EU-Gipfel im September 2006 stellte er - in bewusster Anlehnung an die Ostpolitik Egon Bahrs und Willy Brandts - sein Konzept des „Wandels durch Verflechtung“ vor, das Russland durch ein Netzwerk der wirtschaftlichen, politischen und kulturellen Zusammenarbeit an die EU anbinden sollte. Ein Jahr später initiierte die EU unter der deutschen Ratspräsidentschaft die „Zentralasienstrategie“.

Es gab allerdings keine „Männerfreundschaft“ mehr zwischen dem russischen Präsidenten und dem Bundeskanzler. Angela Merkel, geprägt noch in DDR-Zeiten von ihrer Kenntnis der russischen Sprache und des sowjetischen Alltags, war zudem resistenter gegen Putins robusten Macho-Charme. Mochten sie auch beide Bewunderer der deutsch-russischen Zarin Katarina sein, ihr beider Zugang zur ostmitteleuropäischen Revolution des Jahres 1989 war diametral unterschiedlich. Für den KGB-Offizier in Dresden war sie ein persönliches Desaster und der Beginn „,der größten geopolitischen Katastrophe des 20. Jahrhunderts“ (Putins Rede in der Duma zur Lage der Nation, zit. nach: Wprost 2005, 25. April) - des Zusammenbruchs der UdSSR. Für die Pastoren-Tochter, die in Berlin Naturwissenschaften studierte, bedeutete der Kollaps des Kommunismus - nicht zuletzt mitbeeinflusst durch die polnische Solidarność - einen Aufbruch zur Freiheit.

Die Bundeskanzlerin war es auch, die sich bei Putin dezidiert für polnische Belange einsetzte. Nach der ,Revolution in Orange“ in der Ukraine verhängte Moskau nämlich ein Embargo gegen Fleischimporte aus Polen. Woraufhin Polen 2006 den EURussland-Vertrag blockierte. Während des EU-Russland-Gipfels in Samara im Mai 2007 erinnerten Angela Merkel und José Manuel Barroso Putin daran, dass Polen nicht mehr in der russischen Einflusszone liege, sondern ein EU-Mitglied sei, dessen Fleischprodukte alle EU-Bedingungen erfüllten und in der EU vertrieben würden. Dennoch kam es erst nach dem Regierungswechsel in Polen im Herbst 2007 zu einer Beilegung des polnisch-russischen „Fleischkrieges“, was den Vertreter Russlands bei der EU, Wladimir Tschischow, im russischen Fernsehen zu einer abenteuerlichen These bewegte: Moskau habe mit seinem Embargo eine ihm nicht genehme Regierung in einem EU-Staat gestürzt (wPolityce.pl 2013, 21. Okt.). Selbst wenn diese Deutung aus der Luft gegriffen war, zeigte sie die russische Lesart des ,Wandels durch Verflechtung“. Wirtschaftliche Druckmittel sind geeignete Instrumente, um im ,nahen Ausland" erwünschte politische Zustände zu erzwingen. Der umgekehrte Wandel eine innere Annäherung Russlands an internationale Rechtsnormen und demokratische Gepflogenheiten im Umgang mit der Opposition und den Medien - ließ nicht nur auf sich warten, sondern erlitt Rückschläge. Dass der russische Außenminister Sergej Lawrow für ein „europäisches Konzert der Mächte für das 21. Jahrhundert“ schwärmte (Rotfeld 2007, S. 32), hat man vor allem in Polen als Sehnsucht nach einer Neuauflage russischer Hegemonialansprüche in Europa wahrgenommen. In Deutschland wiederum rief die Verhärtung der russischen Innenpolitik immer größere Enttäuschung hervor. Die Drangsalierung der russischen Opposition, die Morde an kritischen Journalisten und Anwälten sowie die Anschuldigungen gegen ausländische Stiftungen und russische NGOs waren Indizien für eine Abkehr Moskaus von der westlichen Wertegemeinschaft hin zu einer national-autoritären Staatsideologie. 
Zur Zeit der christlich-liberalen Koalition in Berlin 2009-2013 stand die deutsche Außenpolitik im Zeichen der Krise der Euro-Zone, der Polen noch nicht angehört, auch wenn es inzwischen zum zehntgrößten Handelspartner Deutschlands - also noch vor Russland - aufgestiegen ist. Der russisch-georgische „Fünftagekrieg“ im Sommer 2008 hatte jedoch gezeigt, dass der autoritäre Wandel in Russland sich nicht nur auf die Innenpolitik beschränkte. Der offizielle Vorwand war zwar die Verhinderung eines vermeintlichen georgischen „Völkermordes“ an abchasischen und südossetischen Separatisten in Georgien. Doch de facto ging es um die Verhinderung eines NATO-Beitritts Georgiens ,und anderer postsowjetischer Staaten“, wie drei Jahre später der im Mai 2008 zum russischen Staatspräsidenten gewählte und im Westen als liberaler Hoffnungsträger begrüßte Prof. Dmitrij Medwedjew freimütig bekannte (Van Herpen 2014).

Auf dem NATO-Gipfel in Bukarest im März 2008 wurde tatsächlich inoffiziell über die Erweiterung der Allianz palavert. Eine ganze Reihe von Balkan-Staaten waren an einem Beitritt interessiert, außerdem auch Georgien und die Ukraine. Die Allianz sei militärisch größer und mächtiger denn je - doch politisch schwach und zerstritten, befand danach Spiegel Online (2008a, 02. April): Die neuen NATOMitglieder aus Osteuropa und die USA wollten die früheren Sowjetrepubliken an die NATO heranführen, Deutschland, Frankreich und das übrige Westeuropa hielten dagegen, und Putin kündigte russischen Widerstand an: „Das Entstehen eines mächtigen Militärblocks an unseren Grenzen würde in Russland als direkte Bedrohung der Sicherheit unseres Landes betrachtet“ (Spiegel Online 2008b, 04. April). Nach dem russisch-georgischen „Fünftagekrieg“ brach eine scholastische Debatte darüber aus, was ihn denn nun strategisch verursacht habe, die tendenzielle Perspektive der NATO-Erweiterung oder, umgekehrt, ihre Vernebelung.

Auf den Konflikt um Georgien reagierten die ,,alten“ und die „,neuen“ NATO-Mitglieder unterschiedlich. Der polnische Staatspräsident Lech Kaczyński veranlasste seine Amtskollegen aus den baltischen Ländern und der Ukraine zu einem Flug ins umkämpfte Georgien. „Wir wissen sehr gut, heute ist Georgien dran, morgen die Ukraine, übermorgen die Baltischen Länder und später vielleicht auch mein Land, Polen..." rief er auf einem überfüllten Platz (Kaczyński 2008). Der französische Staatspräsident Nicolas Sarkozy wiederum handelte mit dem russischen Staatspräsidenten Dmitri Medwedjew eine Feuerpause im Georgien-Konflikt aus. Sie bedeutete die faktische Amputation des georgischen Territoriums. Bald danach bekam Frankreich einen lukrativen Auftrag für die Lieferung offensiver Hubschraubträger, die für Landungsoperationen im Schwarzen Meer geeignet sind. Auf der anderen Seite paraphierten die USA die Errichtung eines Raketenabwehrschildes in Ostmitteleuropa. Und in Deutschland wurde Angela Merkel für ihre in Tiflis gegebene Zusage, ,,Georgien wird doch - wenn es dafür ist - Mitglied der NATO werden", heftig kritisiert (ARD-Panorama 2008, 28. Aug.). Klassische Kakophonie im Westen also.

Der „Reset“ in den amerikanisch-russischen Beziehungen nach dem Machtwechsel 2009 in Washington, der Barack Obama die Beendigung des Afghanistan-Krieges und die Blockade des iranischen Atomprogramms erleichtern sollte, fiel mit der Bankenkrise nach dem Kollaps von Lehman Brothers zusammen. Die weltweite Finanzkrise und ihre europäische Nachfolge, die „Griechenland-Krise“ überschatteten nach dem Koalitionswechsel in Berlin die ostpolitischen Probleme, obwohl 2009 eine neu- 
erliche russisch-ukrainische Gaskrise auch Gaslieferungen an die EU-Länder betraf. In dieser Phase des verminderten ostpolitischen Engagements des Westens initiierte Polen - von der Finanz- und Euro-Krise relativ wenig gebeutelt - zusammen mit Schweden die „östliche Partnerschaft“ der EU mit Armenien, Aserbaidschan, Georgien, Moldawien und der Ukraine. Unterzeichnet im Mai 2009 in Prag, sollte sie den betroffenen Ländern Visa-Erleichterungen, Handelspräferenzen und - mit nur 600 Mio. Euro ausgestattet - recht symbolische Hilfsprogramme bringen. Die „Partnerschaft" fand auch bald deutsche Unterstützung. In Moskau wurde sie aber wegen der angeblichen Ausgrenzung Russlands mit Misstrauen aufgenommen.

Die 2010 in Rostow am Don von der EU und Russland unterzeichnete „Partnerschaft für Modernisierung“" sollte russische Phobien entkräften und innere Reformen zur Stärkung der freien Marktwirtschaft, der Innovation, der Energieeffizienz, aber auch einer transparenten Justiz und der Zivilgesellschaft in Gang setzen. Diese EUInitiative kam diesmal von Deutschland, doch sie fand auch polnische Unterstützung. Bald erwies sich jedoch, dass Moskau unter „Modernisierung“ ausschließlich technologische Innovation zur Stärkung der Wettbewerbsfähigkeit der russischen Wirtschaft und keineswegs den Ausbau der Zivilgesellschaft versteht. Ein anderer enttäuschender Testfall für die russische Bereitschaft, sich politisch auf die EU zuzubewegen, war für die Bundeskanzlerin der Versuch, zusammen mit Medwedjew den Konflikt zwischen Moldau und dem russisch besetzten Transnistrien beizulegen. Die im Juni 2010 auf Schloss Meseberg ausgehandelten Fortschritte wurden jedoch kaum umgesetzt.

Dass trotzdem auch in den polnisch-russischen Beziehungen ein „Reset“" möglich war, zeigte 2009 die Anwesenheit des russischen Ministerpräsidenten zusammen mit dem polnischen Staatspräsidenten und der deutschen Bundeskanzlerin auf der Danziger Westerplatte anlässlich des 70. Jahrestages des deutschen Überfalls auf Polen. Am Vortag erklärte Putin in einem „Brief an die Polen“ (Gazeta Wyborcza 2009, 31. Aug.) die Umstände des Hitler-Stalin-Paktes, wie Moskau sie sieht, und bezeichnete ihn als unmoralisch. Im April 2010 entzündete er zusammen mit Donald Tusk Kerzen in Katyń, wo 1940 Tausende polnischer Offiziere ermordet worden waren. Doch der Absturz der polnischen Präsidentenmaschine bei Smolensk wenige Tage später vergiftete die Stimmung - trotz der anfänglichen russischen Anteilnahme für die Opfer - nachhaltig. Die russische Untersuchungskommission lieferte weder die Blackbox noch das Wrack der Maschine aus. Und sie fand ausschließlich Schuld bei den polnischen Piloten, die unter Druck der Umgebung des Präsidenten gehandelt hätten. Die Mitbeteiligung der russischen Fluglotsen, die wegen des dichten Nebels die Landung hätten verbieten müssen, blieb unerwähnt.

Trotzdem entwickelte sich der polnisch-russische Dialog, auch mit deutscher Beteiligung, weiter. Im Mai 2011 lud der russische Außenminister Sergej Lawrow seinen polnischen und deutschen Amtskollegen zu einer Debatte an der Kaliningrader Universität ein. Das Ergebnis des „Kaliningrader Dreiecks“ war der im Juni 2012 vereinbarte visafreie „kleine Grenzverkehr“ zwischen beiden Teilen des früheren Ostpreußen.

Die gemeinsamen deutsch-polnischen Aktivitäten Sikorskis und Guido Westerwelles im Rahmen der östlichen Partnerschaft - ob in Weißrussland oder in der Ukraine - hatten jedoch angesichts der gravierenden Spannungen zwischen den 
„Nord- und Südeuropäern“ in der Eurozone und gegenüber dem Tandem MerkelSarkozy bei der Bewältigung der Euro-Krise eine recht marginale Bedeutung im Westen der EU, zumal die „Arabellion“ 2011 in Tunesien, Ägypten und Libyen die europäische Öffentlichkeit in ihren Bann schlug. Diese nordafrikanischen Staaten haben zwar keine Aussicht auf einen EU-Beitritt, aber die von Nicolas Sarkozy 2008 vorangetriebene Idee einer „Mittelmeerunion“" schien nicht mehr nur ein Ersatz für die Aufnahme der Türkei, sondern ein visionäres Zukunftsprojekt für die Südländer der EU zu sein.

Die „Östliche Partnerschaft“ war viel bescheidener, dafür aber konkreter gedacht. Die einbezogenen Länder sind durchaus mögliche Beitrittskandidaten. Die Entscheidung liegt bei ihnen - ob sie es wollen und die Kriterien erfüllen. 2010 wurden auch mit ihnen Verhandlungen über Assoziierungsabkommen aufgenommen - ausgenommen Weißrussland, wo der „letzte Diktator von Europa“ Alexander Lukaschenko regiert, aber inklusive der Ukraine, wo inzwischen der Verlierer der „Revolution in Orange“" von 2004, Viktor Janukowytsch, 2009 die Präsidentschaftswahlen gewann. Während der polnischen EU-Ratspräsidentschaft 2011 wurde der Haushalt der ,östlichen Partnerschaft" auf 1,9 Mrd. Euro aufgestockt, das Assoziierungsabkommen mit der Ukraine jedoch wegen der Inhaftierung der früheren Ministerpräsidentin durch Präsident Janukowytsch zwischenzeitlich auf Eis gelegt. Im Herbst 2013 - während der litauischen Ratspräsidentschaft - sollte es dann doch noch unterzeichnet werden. Der überstürzte Rückzug Janukowytschs infolge der russischen Drohung, im Falle der Unterzeichnung die Energiepreise für die Ukraine anzuheben, führte zu proeuropäischen Massenprotesten in Kiew, zu Janukowytschs Flucht nach Russland, der gewaltsamen russischen Annexion der Krim und der schwersten Ost-West-Krise seit der friedlichen Revolution im Ostblock 1989.

Die Enttäuschung in Deutschland während der christdemokratisch-liberalen Koalition über die Entwicklung in Russland verschärfte sich nach Wladimir Putins Rückkehr an die Macht 2012. Nachdem die Grünen-Abgeordnete Marieluise Beck auf ein Gespräch des einflussreichen deutsch-russischen Lobbyisten Alexander Rahr mit der „Komsomolskaja Prawda“ gestoßen war, schwappte der interne Streit über die Korrektur der deutschen Russlandpolitik in die Öffentlichkeit. Rahr, mit Putin und Medwedjew befreundet und mit der deutschen Politik und Industrie bestens vernetzt, verglich darin den Westen mit der UdSSR, die einst den Anrainerstaaten den Sowjetkommunismus aufzwang, da er „mit allen Methoden, selbst aggressiven“ (Lau 2013) die liberalen Werte aufzwinge. Das war mehr als nur ein Ausrutscher.

Jörg Lau sah darin ein „Kernproblem der deutschen Russlandpolitik“. Lässt Deutschland - schrieb er in der ZEIT - sich von dem verzerrten Bild eines neuen OstWest-Gegensatzes einschüchtern, das die russische Regierung und ihre Apologeten in Deutschland zeichnen? Auf der einen Seite die westliche Wertepolitik, die „quasimilitanten Charakter" habe und angeblich NGO-Aktivisten als „Fundamentalisten im Gewand der alten Kreuzritter" mobilisiere. Auf der anderen Seite die Einschränkung der Presse- und Internetfreiheit in Russland, die Diskriminierung der Homosexuellen und Revitalisierung der imperialen Sehnsüchte. ,Was eigentlich die östlichen, genuin russischen Werte sind, erfährt man nicht. Sie sind ein Popanz, genau wie der angebliche Wertefeldzug des Westens.“ (Lau 2013, S. 4) 
Was im März 2013 noch als bloßer „Kulturkampf“ Putins und Verständnis eines seiner deutschen Akolythen dafür erschien, entpuppte sich ein Jahr später als eine kaum verdeckte militärische Aggression gegenüber einem Nachbarland. Die Ukraine-Krise löste in Deutschland nicht auf Anhieb ein Umdenken der bisherigen Haltung in der Russland-Politik aus. Sie fiel mit einem Koalitionswechsel in Berlin zusammen. Den außenpolitisch unsicheren und innenpolitisch schwachen Partner - die Liberalen - ersetzten selbstbewusstere Sozialdemokraten mit Frank-Walter-Steinmeier durch einen ausgewiesenen Außenpolitiker, der schon Bundeskanzler Schröder beraten hatte und in der Großen Koalition unter Angela Merkel Vizekanzler und Außenminister war.

Der Koalitionsvertrag - große Aufgaben für „die kleinen Leute“, wie Sigmar Gabriel es formulierte (SPD 2013, 27. Nov.) - stand noch ganz im Bann der alten innenpolitischen und wirtschaftlichen Themen: Der Mindestlohn, keine neue Steuern, keine Vergemeinschaftung der Schulden in der EU, aber eine Bankenunion mit einem von den Banken finanzierten Rettungsfond. Der neue außenpolitische Akzent war die Festschreibung - zum ersten Mal in einem deutschen Koalitionsvertrag des französisch-deutsch-polnischen ,Weimarer Dreiecks“ als wichtiges europapolitisches Instrument.

Gerade drei Wochen waren seit dem Gipfel der „Östlichen Partnerschaft“ in Wilna vergangen, auf dem Viktor Janukowytsch den Assoziierungsvertrag mit der EU abgelehnt und damit Massenproteste auf dem Kiewer Majdan ausgelöst hatte, als FrankWalter Steinmeier am 17. Dezember 2013 im Auswärtigen Amt seine Antrittsrede hielt. Sie streifte in einer tour d'horizon alle Bereiche der deutschen Außenpolitik, aber auch die Rolle der Diplomatie bei der Bewältigung aktueller Krisen. Der Anlass war historisch: die „Schlafwandler-Debatte“ vor dem 100. Jahrestag des Ausbruchs des Ersten Weltkrieges. Aber auch ganz aktuell: die anschwellende Krise in der Ukraine. Sie zwang zu einer Neujustierung der deutschen Ostpolitik. Der neue Außenminister erinnerte an sein Projekt einer „Modernisierungspartnerschaft“ mit Russland, die einen Rückfall in die unselige Sprachlosigkeit verhindern sollte, sagte aber unmissverständlich:

Es ist empörend, wie die russische Politik die wirtschaftliche Notlage der Ukraine für sich genutzt hat, um den EU-Assoziierungsvertrag zu verhindern. Und genauso empörend war das gewaltsame Vorgehen der ukrainischen Sicherheitskräfte gegen die friedlichen Demonstranten auf dem Majdan. Aber bei aller Empörung haben uns gerade polnische Politiker, wie Präsident Komorowski ermahnte, dass wir Europäer uns mit Blick auf unsere Ukraine-Politik auch an die eigene Nase zu fassen haben. Wir müssen uns fragen, ob wir unterschätzt haben, wie zerrissen und schwach dieses Land ist; ob wir nicht gesehen haben, dass es dieses Land überfordert, wenn es sich zwischen Europa und Russland entscheiden muss; ob wir die Entschlossenheit Russlands unterschätzt haben, das mit der Ukraine wirtschaftlich, aber auch historisch emotional eng verbunden ist. Ich habe Antworten darauf nicht! Das alles sind Fragen, die wir und die Europäer uns zu beantworten haben... Ich werde noch an diesem Donnerstag nach Polen reisen, um mit unseren polnischen Nachbarn, die mehr als fast alle anderen Europäer von der Ukraine verstehen, zu überlegen, was gemeinsam getan werden kann, um die politische Blockade in Kiew aufzulösen (Steinmeier 2013). 
Bei aller Reverenz gegenüber dem polnischen Ukraine-Verständnis akzentuierten Berlin und Warschau ihre Politiken immer wieder unterschiedlich. Bezeichnend dabei war die deutsch-polnische Rollenverteilung im europaweiten Streit, ob man in einem Land, in dem der Staatspräsident die Oppositionsführerin, Julia Timoschenko, zu einer langjährigen Gefängnisstrafe verurteilen lässt, auch Fußball-Europameisterschaften austragen sollte. Der neue deutsche Staatspräsident Joachim Gauck war dagegen, aber der polnische, Bronisław Komorowski, war dafür. Er argumentierte realpolitisch - wie die SPD 1981 nach der Ausrufung des Kriegszustandes in Polen -, man dürfe die Gesprächsfäden nicht abreißen lassen.

2013 führte die deutsch-polnische ostpolitische Nähe auch zur Wiederbelebung des „Weimarer Dreiecks“. Am 20./21. Februar vermittelten die drei Außenminister Steinmeier, Sikorski und Laurent Fabius in Kiew und handelten mit Viktor Janukowytsch die Modalitäten der Übergangsphase zu Parlaments- und Präsidentschaftswahlen aus. Die Vereinbarung stoppte zwar das Gemetzel auf dem Majdan, hielt aber nur einen Tag, denn Janukowytschs überstürzte Flucht nach Russland und seine Absetzung durch das Parlament wurden von Moskau als Vorwand benutzt, um den Regierenden in Kiew als angeblichen faschistischen Usurpatoren die Legitimation abzusprechen und quasi als Antwort auf die „Kiewer Junta“ den russischen Separatismus im Süden und Osten der Ukraine zu schüren. Auf die militärische Besetzung und völkerrechtswidrige Annexion der Krim folgte die Ausrufung einer „Volksrepublik Donezk“ durch die „Separatisten“ und der - abgewehrte - Versuch einer russischen Irredenta auch in Odessa. Damit war auch das „Budapester Memorandum“ von 1994 gebrochen worden, in dem Russland, die USA und Großbritannien der Ukraine im Gegenzug gegen die Übergabe der ex-sowjetischen Atomwaffen territoriale Integrität garantierten. Moskau leugnete allerdings zunächst seine offenkundige militärische Einmischung - erst Ende August gestand man die Beteiligung russischer ,Freiwilliger" ein - und berief sich auf die vom Internationalen Gerichtshof 2010 völkerrechtlich akzeptierte Abspaltung Kosovos von Serbien. Der Vergleich hinkte, da es anders als im Falle der 1999 von den Serben vertriebenen Kosovaren auf der Krim keine Drangsalierung der russischen Minderheit gegeben hat.

Die Reaktion des Westens auf den russischen Völkerrechtsbruch erinnerte an den „NATO-Doppelbeschlusses“ aus dem Jahre 1979: Dezidiert auf die Herausforderung antworten, aber im Gespräch bleiben. Doch die eher homöopathischen Wirtschaftssanktionen gegenüber Moskau waren alles andere als dezidiert, während sich die deutsche Gesprächsbereitschaft mit Moskau und das Lamento über die fatalen Folgen von Sanktionen für die eigene Wirtschaft etwa die Waage hielten. Prominente Wirtschaftsmanager von Siemens fuhren auch weiterhin nach Moskau, die Sorge um eigene wirtschaftliche Vorteile wurde dabei unter „Vertrauensbildung“ abgebucht. Antworten auf die Frage nach realen Ergebnissen dieser Dialogbereitschaft blieben aus.

Die deutschen „Russlandversteher“ übernahmen - unabhängig von ihren Motivationen - fast nahtlos die Argumentation der russischen Propaganda, wonach die Halbinsel Krim „schon immer“ zu Russland gehört habe, obwohl sie erst Ende des 18. Jahrhunderts erobert und erst mit der Vertreibung der Krimtataren durch Stalin im Zweiten Weltkrieg mehrheitlich russisch besiedelt wurde. Sie übernahmen auch die imperiale Lesart der russischen Geschichtsschreibung, der zufolge die Ukraine 
ein Teil Russlands ist. Und Helmut Schmidt entglitt sogar die Behauptung, dass es keine ukrainische Nation gebe, was den heftigen Widerspruch deutscher Historiker hervorrief, die u. a. darauf hinwiesen, dass bei der Volkszählung 2001 sich 78\% der Bevölkerung als „Ukrainer“ bekannten. 14 Jahre später - infolge der „Revolution in Orange“ 2004 und des „Euromajdan“ 2013/2014 - hat sich der Gerinnungsprozess der Ukrainer zur politischen Nation dramatisch beschleunigt. Auf dem Majdan protestierten nicht nur „Nationalisten“ aus der Westukraine, sondern auch russischsprachige Ostukrainer. Die Bewohner der Ostukraine unterstützten keineswegs geschlossen die massenhaft aus Russland eingeschleusten „Separatisten“, wie den berüchtigten Kommandanten der „Volksrepublik Donezk“ Igor Strelkow, einen FSB-Offizier, der schon gegen die bosnischen und tschetschenischen „Separatisten“, dafür in Transnistrien aber für die russischen gekämpft haben soll (Wikipedia, Igor Strelkov).

Die Aggressivität Russlands führte weltweit zu einem Vertrauensbruch gegenüber der Moskauer Politik und Putin persönlich. Nach einer Erhebung des Pew Research Center vom Juli 2014 war der Anstieg an Misstrauen gegenüber Russland als berechenbarem Partner am stärksten in den USA, in Spanien und Polen. (Pew Research Center 2014). Auch in Frankreich, Großbritannien, Japan, Südamerika - nur in China, Indien und einigen afrikanischen Staaten nicht. In Deutschland war er so stark, dass die Korrespondentin des International Herald Tribune, Judy Dempsey, vor dem Besuch der Bundeskanzlerin in Kiew am 23. August 2014 prompt schrieb: „Russland ist dabei, Deutschland zu verlieren“" (Dempsey 2014). Dieser Wandel zeichnete sich erst nach dem Abschuss der MH17-Maschine im Juli und dem unverfrorenen Umgang der Separatisten mit den Toten ab. Nachdem auch Westeuropäer Opfer des Krieges in der Ostukraine geworden waren, stieg in Deutschland die Bereitschaft zu härteren Sanktionen.

Merkwürdigerweise ließ ausgerechnet in dieser Phase die deutsch-polnische Gemeinsamkeit nach. Im Streit um die Aufrechterhaltung der kulturellen Kontakte mit Russland entschied sich Berlin genau umgekehrt zu Warschau. Während das deutsche AA am ,Jahr der deutschen Sprache und Kultur in Russland“ festhielt, stornierte das polnische Außenministerium das parallele ,polnische Jahr“. Diesen Zwist sollte man jedoch nicht überbewerten, denn beide Jahre waren anders konzipiert, und in beiden Ländern gab es ähnliche Argumente pro und contra unter Künstlern und Intellektuellen. Andrzej Wajda bedauerte die polnische Entscheidung, während Karl Schlögel engagiert für mehr Distanz im deutschen Kulturaustausch mit Russland plädierte. Auch die offizielle polnische Reaktion blieb elastisch - der kleine visafreie Grenzverkehr mit der Kaliningrader Region blieb erhalten, und während der gut besuchten Tage der russischen Literatur in Zoppot im August erklärte Wladimir Sorokin die russische Befindlichkeit: „In den neunziger Jahren ist die Leiche des Totalitarismus nicht beerdigt worden. Man warf sie in eine Ecke und wartete darauf, dass sie sich von selbst zersetzt. Sie hat sich aber gut gehalten. Die Folgen sieht man heute" (Rudziński 2014). Im November wird man in Kaliningrad während eines von den Konsulaten Deutschlands und Polens mitorganisierten Hannah-Arendt-Seminars über diese gut konservierte Leiche des Totalitarismus, über das Wesen der europäischen Revolutionen und über politische Schuldfragen diskutieren. 
Aus der Sicht der nationalkonservativen Opposition hat jedoch die Regierung Tusk versagt, weil bei neuerlichen Gesprächen von Lawrow, Steinmeier und Fabius der polnische Außenminister fehlte. Die linksliberalen Medien konterten nach dem Treffen von Putin und Poroschenko in Minsk: „Die Berliner Gespräche waren keine Rückkehr zum ,Konzert der Mächte', das Europa regieren soll. Unter den Bedingungen der Konfrontation mit Russland muss irgendjemand die Europäische Union führen, und die Europäische Kommission eignet sich dafür nicht. In der ,harten' Politik, wenn auch militärische Optionen offen gehalten werden, zählt die Stimme der Mitgliedstaaten und nicht der Union als Ganzes. In dieser Situation kann nur Deutschland in Kooperation mit den Amerikanern die Union führen. Seit Ende Februar erfüllt Angela Merkel diese Aufgabe“ (Czech 2014), schrieb in der „Gazeta Wyborcza“ Mirosław Czech, ein Politiker und Kommentator ukrainischer Abstammung.

Doch die Verdächtigung, Deutschland sei ein schwankender Teil des Westens, beschränkt sich nicht allein auf die Opposition. Dass Moskau in der „Telefondiplomatie" Berlin sichtlich den Vortritt lässt, ist nicht das Problem. So errechnete die „Welt“" unlängst, dass Angela Merkel seit Januar 33 Telefonate mit Putin geführt hat, Holland dagegen 15, Obama 10, Nasarbajew 9, Lukaschenko 7, Poroschenko und Cameron jeweils 6. (Smirnova 2014). Das Problem sei die Abhängigkeit der deutschen - aber auch der italienischen, ungarischen oder holländischen - Politik von Erpressungen durch Gasprom. „Wir können nicht auf Deutschland zählen“ (Kuźniar 2014), schrieb in der „Rzeczpospolita“ eine Woche vor dem NATO-Gipfel in Newport Prof. Roman Kuźniar, einer der Berater von Präsident Komorowski.

Kuźniars Beitrag hatte eine aktuelle Note:

„wir müssen zur Kenntnis nehmen, dass wir wegen der besonderen Beziehung Berlins zu Russland in Sicherheitsfragen der Region nicht auf Deutschland zählen können. Wir haben jedoch das Recht zu erwarten, dass es unsere Bemühungen um eine Stärkung der NATO-Ostflanke, die sowohl in unserer historisch-geopolitischen Erfahrung als auch in der gegenwärtigen Politik Russlands begründet sind, nicht behindert. Das verlangt von Deutschland die Geschichte“ (Kuźniar 2014).

Indirekt konnte man Kuźniars Essay als eine Ergänzung der deutschen Debatte um die außen- und militärpolitische Neuorientierung der Bundesrepublik lesen, die der Außen- und die Verteidigungsministerin sowie der Bundespräsident angestoßen haben, aber auch als einen Beitrag zur deutschen Auseinandersetzung um das Verständnis der russischen Geschichte.

Auf eine Korrektur der klassischen Sicht, die Ukraine sei „eigentlich“ ein Teil Russlands, drängte im Spiegel (Snyder 2014) der amerikanische Historiker Timothy Snyder, Autor einer Geschichte ostmitteleuropäischer Nationen (Snyder 2003). Und auf der deutschen Seite vertrat dies Heinrich August Winkler. Der Autor der „Geschichte des Westens“ verortete das merkwürdige Verständnis in Deutschland für die russische Einnahme der Krim in der völkischen Denktradition des 19. und 20. Jahrhunderts und korrigierte die oft nach Putin wiederholte Legende, der Westen habe ein Versprechen gebrochen, die NATO nach der Vereinigung Deutschlands nicht weiter nach Osten zu erweitern. Denn ein solches Versprechen hat es nicht gegeben. Hans-Dietrich-Genscher äußerte dies zwar im Februar 1990 in einem Gespräch mit 
dem sowjetischen Außenminister, aber auf die deutsche Stimme kam es damals gar nicht an. Es gab ja noch kein souveränes Deutschland. Und der amerikanische Präsident George Bush hat derartiges nie zugesagt. Nach der Auflösung des Warschauer Pakts und der UdSSR legte sich Moskau quer, als die ehemaligen Ostblockstaaten in die NATO drängten.

Im März 1997 aber ebnete der russische Präsident Boris Jelzin bei einem Gipfeltreffen mit dem amerikanischen Präsidenten Bill Clinton in Helsinki den Weg für eine Beilegung des Konflikts. Zuvor hatte das atlantische Bündnis erklärt, dass es, solange die gegenwärtige Sicherheitslage andauere, in den neuen Mitgliedstaaten weder größere Depots anzulegen, noch umfangreiche Truppenverbände oder Atomwaffen zu stationieren gedenke. Ende Mai 1997 schloss Jelzin in Paris mit der NATO ein Sicherheitsabkommen, das diese Absichtserklärung wiederholte. Die ehemaligen Mitglieder des Warschauer Pakts, die sich ab 1999 der NATO anschlossen, machten damit von ihrer neugewonnenen Souveränität und von einem Recht Gebrauch, das ihnen die Sowjetunion 1975 in der Helsinki-Schlussakte ausdrücklich zugestanden hatte: dem Recht, Vertragspartner eines Bündnisses zu sein. Bei Putins deutschen Apologeten geht das Verständnis, das sie für russische Sicherheitsinteressen aufbringen, mit einem Mangel an Verständnis für die Sicherheitsbedürfnisse der Staaten Ostmittel- und Südosteuropas einher. Die Folge sind neue Zweifel an der Berechenbarkeit Deutschlands, vor allem in Polen und den baltischen Republiken. Wer, wie manche Vertreter des konservativen Flügels der Russland-Versteher, an die vermeintlich gute Tradition deutsch-russischer Sonderbeziehungen anknüpfen möchte, setzt damit den Zusammenhalt des atlantischen Bündnisses und der Europäischen Union aufs Spiel (Winkler 2014).

Nach Winkler folgt Putin einer neoimperialen Ideologie, die in ihrer antiliberalen Ausrichtung bei einigen westlichen Konservativen ähnlich viel Anklang findet wie zur Zeit der Heiligen Allianz. Im russisch-ukrainischen Konflikt geht es Winkler zufolge um die Grenze zwischen Ost und West, zwischen dem ,lateinischen Europa“ (Winkler 2014), das seit dem Mittelalter Gewaltenteilung, Pluralismus und Individualismus, Rechtsstaat, Menschenrechte und schließlich Volkssouveränität und repräsentative Demokratie ausgearbeitet hat, und dem ,orthodoxen Osten und Südosten Europas“ (Winkler 2014), das all das nicht kannte. Diese Grenze aber ist keine Linie, sondern ein historisch, kulturell, politisch und sogar sprachlich ausdifferenzierter Raum - die Ukraine (Winkler 2014).

Als es um die NATO-Mitgliedschaft der ostmittel- und südosteuropäischen Staaten ging, konnte der Westen Russland kein Vetorecht zubilligen. Die friedlichen Revolutionen von 1989 hatten die Ordnung von Jalta, die im Februar 1945 von den USA, der Sowjetunion und Großbritannien verfügte Teilung Europas, zum Einsturz gebracht. Der Fall der Ukraine ist anders gelagert. Die Einbeziehung dieser historisch eng mit Russland verbundenen ehemaligen Sowjetrepublik in die NATO müsste Russland in der Tat als „Einkreisung“ empfinden. Auf einem anderen Blatt steht eine Mitgliedschaft in der EU. Würde sich die Ukraine systematisch bemühen, die Kopenhagener Beitrittskriterien von 1993 zu erfüllen, könnte ihr die EU den Kandidatenstatus schwerlich verwehren. (Winkler 2014) 
Zur Debatte stand im August 2014 nicht der NATO-Beitritt der Ukraine, sondern die Frage, ob sie überhaupt über ihren Weg ohne russische Annexionen und militärischen Druck aus Moskau frei entscheiden kann. Und damit drängt sich die Frage nach der Wandlungsfähigkeit Russlands auf. Roman Kuźniars überzogene Reiterattacke gegen die ,atavistische Russophilie Berlins“ hat eine geschichtsphilosophische Spitze:

Das Wohlwollen unserer westeuropäischen Partner gegenüber Putins Russland ist im Grunde genommen von Pessimismus im Hinblick auf dessen Natur unterlegt. Für sie kann Russland nur so sein, wie sein derzeitiger Präsident. Wir sind anderer Ansicht. Die Russen bewahren das Potential, auch in politischer Hinsicht ein normales Land zu werden, das nicht zu unberechenbarem Autoritarismus und der Herrschaft einer Soldateska verurteilt ist, sondern das Völkerrecht und das Recht seiner Nachbarn respektiert, ihren Entwicklungsweg und ihre Außenpolitik zu wählen. Ein Land, das irgendwann ein wertvoller Partner Europas werden kann. Der Weg dorthin ist keine Neuauflage der Appeasement-Politik, sondern ein entschlossenes, kohärentes und hinreichend beständiges Containment der expansiven, gegenüber den Nachbarn und Europa feindseligen Ambitionen des Kreml. Es wäre lohnend, wenn westliche Politiker sich für die Teilnahme an den Gedenkfeiern wichtiger Jahrestage nicht nur auf das Ritual beschränkten, sondern auch die Mühe machten, die mit ihnen verbundenen Worte zu begreifen. (Kuźniar 2014)

Der Hinweis war eindeutig: Es genügt nicht, zum 75. Jahrestag des Überfalls auf Polen und seine ,vierte Teilung“ durch Hitler und Stalin nur über Geschichte zu sprechen. Moskau ließ ja in der Ostukraine die Maske fallen. Mit schwerem Kriegsgerät führte es eine militärische Wende zugunsten der Separatisten herbei. Bald darauf forderte Putin Kiew zu Gesprächen ,über die Staatlichkeit im Südosten der Ukraine“ (tvn24 2014) auf und deutete zugleich an, dass er in zwei Wochen in Kiew einmarschieren könnte. Gespenstische Analogien drängten sich auf, als auch Karten einer „Zu regionalisierenden“ (Fakt.pl 2014) Ukraine - im Klartext das Angebot einiger Duma-Abgeordneten einer Aufteilung der Ukraine zwischen Russland, Polen, Rumänien und Ungarn - auftauchten.

Der Besuch der Bundeskanzlerin in Lettland und Kiew, der Übergang zur nächsten Stufe der Wirtschaftssanktionen und die Ankündigung einer ständigen NATO-Präsenz im Baltikum, in Polen und Rumänien sowie die Wahl des polnischen Ministerpräsidenten für 2,5 Jahre zum „EU-Präsidenten“ war die Antwort. Das Freiheitsthema verbinde ihn mit Bundespräsident Joachim Gauck, die Erfahrung als langjähriger Machttechniker eher mit Angela Merkel, kommentierte die Süddeutsche Zeitung.

Diese Mischung ist eine, die der EU tatsächlich nützlich werden könnte. Tusk wird die Staats- und Regierungschefs in Zeiten größter Herausforderungen zusammenhalten müssen. Die EU muss sich darauf einstellen, dass Kremlchef Putin weitere Gebiete der Ukraine unter Kontrolle bringen wird. Sie muss damit rechnen, dass schon im nächsten Winter einzelne Mitgliedstaaten vor Problemen mit der Gasversorgung stehen werden. Und sie muss sich klarmachen, dass sie zur Insel inmitten eines Krisenmeers geworden ist, wie die Barbarei des Islamischen Staates (IS) im Irak zeigt. (Süddeutsche Zeitung 1.9.14) 
In Polen verglichen manche die Wahl Tusks zum „Präsidenten Europas“ mit der Papstwahl 1978. Auch wenn die Eigengewichte beider Ämter unvergleichbar sind, war in beiden Fällen die deutsche Unterstützung für den jeweils Gewählten von entscheidender Bedeutung. Jene deutsch-polnische Gemeinschaft, die sich mit der „,neuen deutschen Ostpolitik“ und der Botschaft der polnischen Bischöfe abzeichnete und während des „wunderbaren Jahres“ (Winkler 2007) 1989 zur Lösung beider Jahrhundertfragen, wie Heinrich August Winkler es ausdrückte, der deutschen Einheit und der Freiheit für Polen beitrug, hält also nicht nur in der europäischen Ostpolitik - trotz aller Disparitäten, Differenzen und medialer Rückfälle in gegenseitige Verdächtigungen.

Und die kommen immer wieder zum Vorschein. Bezeichnend dafür war die innerdeutsche Reaktion auf die Rede des Bundespräsidenten am 1. September auf der Danziger Westerplatte anlässlich des 75. Jahrestages des deutschen Überfalls auf Polen. Joachim Gauck würdigte den polnischen Widerstand gegen Hitler und den polnischen Beitrag zur Befreiung vom Kommunismus 1989, konnte aber an diesem Ort nicht zur russischen Aggression gegen die Ukraine schweigen:

Nach dem Fall der Mauer hatten die Europäische Union, die NATO und die Gruppe der großen Industrienationen jeweils besondere Beziehungen zu Russland entwickelt und das Land auf verschiedene Weise integriert. Diese Partnerschaft ist von Russland de facto aufgekündigt worden. Wir allerdings wünschen uns auch in Zukunft Partnerschaft und gute Nachbarschaft. Aber die Grundlage muss eine Änderung der russischen Politik und eine Rückkehr zur Achtung der Prinzipien des Völkerrechts sein. (Gauck 2014)

Die Kritik, die diese Rede in der linken und linksliberalen Szene hervorgerufen hat, zeigt, wie brüsk man wegen innenpolitischer Rechthaberei die delikate Materie nicht nur der deutsch-polnischen, sondern der ostmitteleuropäischen Belange insgesamt beiseite wischen kann. Für viele PDS-Genossen der ersten Stunde war der Zusammenbruch der DDR, des Ostblocks und schließlich auch der UdSSR kein Glücksfall der Geschichte, sondern eher eine unfassbare Panne. Sie mögen sich zwar heute auf Rosa Luxemburg berufen, aber das äußerste, was sie sich damals vorstellen konnten, war eine Liberalisierung von oben, angefangen in Moskau. Zum östlichen „Bruderland“ - zu Polen mit seiner Solidarność, seinem Papst und seiner Nonchalance gegenüber den Klassikern der ,wissenschaftlichen Weltanschauung“ - hatten sie keine Beziehung. Die haben auch ihre jüngeren Nachfolger in der Linken Partei nicht. Sie haben kaum Partner in Polen gefunden, auch selten danach gesucht. Daher besteht auch kein Zwang, sich genau überlegen zu müssen, wo und zu wem Joachim Gauck in Danzig sprach und das sagte, was er sagen musste.

Die Westerplatte ist in Polen der Inbegriff eines bedingungslosen Widerstandes, was der polnische Papst am 24 Juni 1987 bei einem seiner Besuche in der Heimat auf den Punkt brachte: „Im Leben jedes Menschen gibt es eine Westerplatte“, das heißt - Momente, in denen Widerstand auch unter Einsatz des eigenen Lebens unvermeidlich ist, wenn man sich treu bleiben will. Joachim Gauck kannte sicherlich diese Worte und spürte, als Bundespräsident und ehemaliger Pastor, dass es nicht ausreicht, aus Versatzstücken eine 08/15-Mahnrede zur Versöhnung zu halten. Das wäre angesichts des russischen Zugriffs auf die Ostukraine eine Zumutung nicht nur 
für die Polen, sondern auch für die Ostmitteleuropäer und nicht zuletzt auch für die Deutschen gewesen. Denn es gibt tatsächlich Momente, in denen nichts außer non possumus bleibt.

Die Süddeutsche Zeitung fand die Westerplatte-Rede ,unbesonnen“, weil der Bundespräsident ,nur noch in der Vergangenheitsform von einem europäischen Russland“ sprach, aber angesichts der deutschen Verbrechen ,,an der russischen Grenze keine Vollbremsung machen“ darf (Prantl 2014). Ausgerechnet am 1. September von einem Bundespräsidenten in Polen ein Loblied auf deutsch-russische Versöhnung einzufordern, ist ein Unfug. War denn gerade am 1. September 1939 Stalin etwa kein stiller Verbündeter Hitlers? Und an welcher russischen Grenze müsste Joachim Gauck dann ,vollbremsen“? An der polnisch-sowjetischen, die Stalin sich damals gerade zu überschreiten anschickte, oder an der deutsch-russischen Demarkationslinie von 1941, die die beiden Völkermörder nach der einvernehmlichen Zerschlagung Polens mitten durch Polen zogen? Zu solchen Entgleisungen kommt es nur, wenn jemand den ganzen Komplex Ostmitteleuropa noch immer nicht verinnerlicht hat.

Die Kritiker Gaucks hoben hervor, dass Deutschland ja gemeinsame Sicherheitsinteressen mit Russland habe. Doch gibt es die mit dem unerklärten Krieg Russlands gegen die Ukraine wirklich noch? Michail Popow, der stellvertretende Sekretär des Nationalen Sicherheitsrats, hat unlängst die Grundzüge der neuen russischen Bedrohungsanalyse dargelegt. Er nannte den „Arabischen Frühling“ sowie die Konflikte in Syrien und den Euro-Majdan in Kiew. Die ,,indirekten Handlungen“ der „führenden Staaten“ des Westens hätten die Ukraine destabilisiert, indem radikale Organisationen und private Militärunternehmen das „Protestpotential der Bevölkerung“ ausnutzten. Die zweite Bedrohung stellt nicht die NATO als solche dar, sondern ihre Annäherung an die Grenzen Russlands; nicht als militärische Gefahr - könnte man hinzufügen -, sondern als ein Zeichen, dass die ehemaligen Kolonien auch der Grauzone des „nahen Auslandes“ entlaufen sind. Die neue russische Militärdoktrin definiert sogar die Bedingungen für einen ,,präventiven Nuklearschlag“ (Schmidt 2014). Das Wunschziel der russischen Nationalisten nannte im August Wladimir Schirinowskij in einem vom russischen Fernsehen am 14. August 2014 aus Jalta übertragenen Gespräch russischer Abgeordneter mit Putin: Er hoffe, dass im Falle eines Krieges mit dem Westen Polen und die baltischen Staaten ausradiert würden (Zyrinowski 2014). Nach einem scharfen Protest des polnischen Außenministeriums machte Schirinowskij einen Rückzieher, er sei falsch verstanden worden. Man darf dieser Episode nicht allzu große Bedeutung beimessen, allerdings gibt sie einen Einblick in die Emotionen, die in Russland - nicht im Westen - geschürt werden.

Dass Joachim Gauck auf der Westerplatte den richtigen Ton getroffen hat, bezeugte ihm der polnische Staatspräsident in seiner Rede am 11. September im Deutschen Bundestag:

Genauso wie Herr Bundespräsident Joachim Gauck bin auch ich überzeugt, dass wir nur gemeinsam das demokratische und friedliche Europa der Zukunft bauen können. Und nur gemeinsam können wir es verteidigen. Wir brauchen eine deutsch-polnische Verantwortungsgemeinschaft für die Zukunft Europas. (Komorowski 2014) 
Diese Verantwortungsgemeinschaft sieht Bronisław Komorowski in der Vertiefung der EU, aber auch der Stärkung der atlantischen Allianz, er sprach sich für den Freihandelsvertrag mit den USA aus und erinnerte die Deutschen daran, dass sie selbst Nutznießer des amerikanischen Sicherheitsschirms waren:

\begin{abstract}
Abschreckung bildet keinen Widerspruch zu Zusammenarbeit und Dialog, sondern ist deren notwendige Ergänzung. Denn es gibt Mächte in der Welt, die auf eingegangene Verpflichtungen keine Rücksicht nehmen, sobald sie bei ihren Partnern militärische Schwäche oder fehlende Entschlossenheit verspüren. (...) Auch wir würden gerne in Russland einen Freund des im weitesten Sinne des Wortes verstandenen Westens sehen. Deshalb stellt die aktuelle Politik Russlands für uns eine so tiefe Enttäuschung und auch eine vielschichtige Herausforderung dar. Wir bedauern es sehr, dass sich die derzeitige Führung im Kreml für den Antiokzidentalismus als Legitimation für die eigene Machtausübung, als eine eigene Identität und geopolitische Orientierung entschied, dass sie den Weg der Dominanz und der Weiterentwicklung der eigenen Bedeutung nicht durch eine Modernisierung und durch die Zusammenarbeit mit dem Westen, sondern durch die Wiedererrichtung der alten Einflusszone, wenn auch in einem neuen Gewand, wählte, indem sie militärische Gewalt gegen die Nachbarn einsetzt. (...) Ähnlich denken viele unserer russischen Freunde, und sie befürchten, dass die jetzige Politik des Kremls eine Gefahr für deren Rechte als Bürger und deren Freiheit darstelle. Wir müssen in russischsprachige Medien investieren, deren Sendebereich sich sowohl auf Europa wie auch über seine Grenzen hinaus erstreckt, um den Raum der Meinungsfreiheit auszuweiten und gegen Lügen vorzugehen. (...) Daher ist die Hilfe für die Ukraine und andere Länder der Östlichen Partnerschaft in jeder denkbaren Hinsicht erforderlich: angefangen von der humanitären Hilfe, der Unterstützung beim Wiederaufbau nach dem Krieg bis hin zur Vermittlung von Erfahrungen, wenn es um Reformen der Kommunalverwaltung, um die Entwicklung von kleinen und mittelständischen Unternehmen, um die Bekämpfung von Korruption oder auch um die Reform des Verteidigungssystems. (Komorowski 2014)
\end{abstract}

Diese polnische Rede im Bundestag ergänzte nicht nur die Gedankengänge des deutschen Präsidenten auf der Westerplatte. Sie präzisierte auch die Denkrichtung des Berliner Aufrufs des polnischen Außenministers Radoslaw Sikorski vom Dezember 2011 und ist wohl auch eine gute Stütze für Donald Tusk in seiner neuen Funktion eines „Präsidenten Europas“.

Den Linken behagte ex definitionem Komorowskis Argumentation nicht. „Es war ein Appell für eine Politik der Aufrüstung“, sagte in n-tv eine Abgeordnete der Linken: „Aus meiner Sicht ist das in der aktuellen Situation die grundfalsche Position. Wenn wir einen Gedenktag begehen, sollte es doch die Lehre sein, Krieg zu vermeiden. Da hätte ich mir von Herrn Komorowski eine andere Tonalität gewünscht... “ (Gohlke 2014). Dass Nicole Gohlke nicht zuhörte, weil sie nicht zuhören wollte, konnte sie aus einem Kommentar der Süddeutschen Zeitung erfahren:

Klug unterscheidet Komorowski zwischen Putin, dessen nationalistische Ideologie an die Dreißigerjahre erinnert, und Russland. Von dem was er vorschlägt, um 
dem Angriff, auf die Fundamente einer demokratischen Gemeinschaft' zu begegnen, muss sich in Russland niemand bedroht fühlen, höchstens Putin und die Männer des FSB. Für die Deutschen erklärte Polens Präsident, was ,Realpolitik' ist: die kluge, langfristige und wirksame Verteidigung der menschlichen Würde. Komorowski wünscht Entschlossenheit und eine klare Sprache, den Aufbau russischsprachiger Medien, um der Kreml-Propaganda etwas entgegenzusetzen, und Hilfe für die Ukraine. Verstören dürfte Teile der deutschen Öffentlichkeit das klare Bekenntnis zur NATO und zur Stärkung der Ostflanke des Bündnisses. Die polnische Gesellschaft ist Militäreinsätzen ebenso abgeneigt wie die deutsche, doch verfolgt man aufmerksam die Diskussionen in Deutschland und fragt sich, ob die Deutschen bereit wären, Polen beizustehen (Bisky 2014).

Und die „Frankfurter Allgemeine“ meinte:

Komorowski lobte die Deutschen dafür, dass sie sich mutig mit ihrem ,geschichtlichen Drama' auseinandersetzten. Doch was folgt aus dem Hineinschlittern der europäischen Mächte in den Ersten Weltkrieg vor einem Jahrhundert, was aus der lange ungebremsten Aggression Deutschlands 25 Jahre später? Die Vereinten Nationen wären eine Antwort, doch sind sie oft blockiert, weil ihr wichtigstes Gremium überholte Machtverhältnisse widerspiegelt. Die UN sind keine wehrhafte Wertegemeinschaft - anders die EU und die NATO. Hier haben sich ehemalige Kriegsgegner so miteinander verflochten, dass sie Konflikte untereinander nur noch friedlich lösen (können). Dieses Modell ist überaus erfolgreich, muss aber auch Tag für Tag verteidigt werden. Davon lässt sich auch Putin beeindrucken, hat doch Russland nicht nur aus polnischer Sicht vor allem Angst vor demokratischer Modernisierung. Die Verteidigungsbereitschaft der früheren Opfer Hitlers und (hoffentlich) des westlichen Bündnisses ist gerade kein Säbelrasseln. Hier geht es um Freiheit oder Unterdrückung. Also um Sein oder Nichtsein. (Müller 2014)

Die Jahrestage 1914, 1939, 1989, 2004 sind im Sommer und Herbst des Jahres 2014 nur eine Kulisse. Die reale Haupt- und Staatsaktion dieses Jahres auf der europäischen Bühne ist vielmehr der russische Versuch, die ,größte geopolitische Katastrophe des 20. Jahrhunderts“ (Putins Rede in der Duma zur Lage der Nation, zit. nach: Wprost 2005, 25. April), den Zerfall des russisch-sowjetischen Imperiums, doch noch zurückzudrehen. Die ostmitteleuropäische Revolution des Jahres 1989 hat weder ihre Guillotine noch ihren Bonaparte hervorgebracht, aber 25 Jahre danach eine konservative Gegenrevolution, die mit Gewalt einen imperialen Rollback versucht. Deutsche und Polen, laut August Heinrich Winkler die beiden größten Akteure und Nutznießer des Herbstes der Völker 1989, werden daran gemessen, ob sie zu den Werten und Errungenschaften ihrer gemeinsamen Revolution als Interessen-, Streitund nun auch „Verantwortungsgemeinschaft“ stehen werden.

Open Access Dieser Artikel unterliegt den Bedingungen der Creative Commons Attribution License. Dadurch sind die Nutzung, Verteilung und Reproduktion erlaubt, sofern der/die Originalautor/en und die Quelle angegeben sind. 


\section{Literatur}

ARD-Panorama. (2008, 28. August). Neuer kalter Krieg? - Deutschlands riskanter Kurs. http://daserste. ndr.de/panorama/archiv/2008/panoramageorgien100.html. Zugegriffen: 20. Sept. 2014.

Bahr, E. (1981). Vorwärts, 24. Dezember 1981.

Bahr, E. (1996). Zu meiner Zeit. München: Karl Blessing Verlag.

Bisky, J. (2014). Fortwährende Entgiftung. Süddeutsche Zeitung, 11. September 2014.

Cichocki, M. (2004). Porwanie Europy. Centrum stosunków międzynarodowych, Kraków-Warszawa.

Czech, M. (2014). Jaki sens ma spotkanie w Mińsku Unii Euroazjatyckiej z Unią Europejską. Gazeta Wyborcza, 22. August 2014. http://wyborcza.pl/1,75968,16511028,Jaki_sens_ma_spotkanie_w_ Minsku_Unii_Euroazjatyckiej.html. Zugegriffen: 4. Okt. 2014.

Dempsey, J. (2014). Judy Dempsey: Russia is losing Germany. Kyiv Post, 21. August 2014. http://www. kyivpost.com/opinion/op-ed/judy-dempsey-russia-is-losing-germany-361512.html. Zugegriffen: 20. Sept. 2014

Fakt.pl. (2014, 27. April). Oto plan rozbioru Ukrainy! Są mapy i konkretne propozycje.... http://www. fakt.pl/rozbior-ukrainy-skandaliczna-mapa-i-skandaliczna-propozycja-putina, artykuly,457850,1. html. Zugegriffen: 22. Okt. 2014.

Frei, N. (2012). Der Koloss von Bonn. Süddeutsche Zeitung, 25. September 2012.

Gauck, J. (2014). Bundespräsident Joachim Gauck anlässlich der Gedenkfeier zum deutschen Überfall auf Polen 1939 am 1. September 2014 in Danzig/Polen. http://www.bundespraesident.de/SharedDocs/ Reden/DE/Joachim-Gauck/Reden/2014/09/140901-Gedenken-Westerplatte.html. Zugegriffen: 22. Sept. 2014.

Gazeta Wyborcza (2009, 31. August). Brief an die Polen.

Gohlke, N. (2014). Linken-Abgeordnete sauer. „Komorowski-Rede war Aufrüstungsappell“. Interview mit n-tv am 10. September 2014. http://www.n-tv.de/politik/Komorowski-Rede-war-Aufruestungsappell-article13579871.html. Zugegriffen: 22. Sept. 2014.

Hamburger Abendblatt. (2004, 23. November). Schröder: „Putin ist lupenreiner Demokrat“. http://www. abendblatt.de/politik/deutschland/article290532/Schroeder-Putin-ist-lupenreiner-Demokrat.html. Zugegriffen: 22. Sept. 2014.

Herold, F. (2006). Die Ostsee-Pipeline und der Hitler-Stalin-Pakt. Berliner Zeitung, 2. Mai 2012.

Herpen, M. H. V. (2014). Putin's Wars. The Rise of Russia's New Imperialism. Rowman \& Littlefield.

Hofmann, G. (2011a). Richard von Weizsäcker. Ein deutsches Leben. München: C. H. Beck.

Hofmann, G. (2011b). Polen und Deutsche auf dem Weg zur europäischen Revolution. Berlin: Suhrkamp.

Jäger, T., \& Dylla, D. W. (2008). Deutschland und Polen: Die europäische und internationale Politik. Berlin: Springer.

Kaczyński, L. (2008). https://www.youtube.com/watch?v=LEhJ-5xIJtg. Zugegriffen: 22. Okt. 2014.

Komorowski, B. (2014). Rede von Polens Staatspräsident Bronisław Komorowski bei der Gedenkfeier „75 Jahre Beginn Zweiter Weltkrieg“ (Polnisch) am 10. September 2014. http://www.bundestag.de/ dokumente/textarchiv/2014/kw37_gedenkstunde_komorowski/297050. Zugegriffen: 20. Sept. 2014.

Kuźniar, R. (2014). Rzeczpospolita, 26. August 2014.

Lau, J. (2013, 14. März). Wie soll Deutschland mit Russland umgehen? Die ZEIT, 4.

Müller, R. (2014). Sein oder Nichtsein. Frankfurter Allgemeine Zeitung, 11. September 2014.

Noack, H. -J. (2013). Willy Brandt. E in Leben, ein Jahrhundert. Berlin: Rowohlt.

Pew Research Center. (2014). Russia's global image negative amid crisis in Ukraine. American' and Europeans' views sour dramatically. 9. Juli 2014. http://www.pewglobal.org/files/2014/07/PG-2014-0709-Russia-Favorability.pdf. Zugegriffen: 19. Sept. 2014.

Prantl, H. (2014). Der unbesonnene Präsident. Süddeutsche Zeitung, 2. September 2014.

Preuße, D. (2014). Umbruch von unten. Berlin: Springer.

Rotfeld, A. D. (2007). Niemcy - Polska - Rosja „Refleksje o przeszłości, współczesności i przyszłości“. In W. M. Góralski (Hrsg.), Polska - Niemcy 1945-2007. Od konfrontacji do wspólpracy i partnerstwa w Europie. Warschau: PISM.

Roxburgh, A. (2012). The Strongman. Vladimir Putin and the Struggle for Russia. I.B. Tauris.

Rudziński, L. (2014). Co myślą o nas Rosjanie? Weekend literatury w Sopocie za nami. Trojmiasto.pl, 25. August 2014. http://kultura.trojmiasto.pl/Co-mysla-o-nas-Rosjanie-Weekend-literatury-w-Sopocieza-nami-n82744.html. Zugegriffen: 22. Okt. 2014.

Schmidt, F. (2014.). Des Kremls neue Militärdoktrin. Frankfurter Allgemeine Zeitung, 6. September 2014. 
Sikorski, R. (2011). „Polska a przyszłoś“ Unii Europejskiej. Radosław Sikorski, Minister Spraw Zagranicznych RP. 28. Dezember, 2011. http://www.msz.gov.pl/resource/c2a33d88-7b8d-4fa5-8680a67a4b2b38af:JCR. Zugegriffen: 21. Sept. 2014.

Smirnova, J. (2014). Merkels Wort hat bei Putin das stärkste Gewicht. DIE WELT, 21. August 2014. http:// www.welt.de/politik/ausland/article131434934/Merkels-Wort-hat-bei-Putin-das-staerkste-Gewicht. html. Zugegriffen: 22. Sept. 2014.

Snyder, T. (2003). The Reconstruction of Nations: Poland, Ukraine, Lithuania, Belarus, 1569-1999. Yale University Press.

Snyder, T. (2014, 17. Februar). Spielchen mit der Vergangenheit. Der Spiegel, 8.

SPD. (2013, 27. November). Sigmar Gabriel: Koalitionsvertrag für die „kleinen Leute“ und Koalition für große Aufgaben. Pressemitteilung 645/13. http://www.spd.de/presse/Pressemitteilungen/112820/20131127_gabriel_koalitionsvertrag.html. Zugegriffen: 20. Sept. 2014.

Spiegel Online. (2008a, 2. April). Nato-Gipfel: Bush geht auf Konfrontationskurs zu Putin. http://www. spiegel.de/politik/ausland/nato-gipfel-bush-geht-auf-konfrontationskurs-zu-putin-a-544797.html. Zugegriffen: 20. Sept. 2014.

Spiegel Online. (2008b, 4. April). Umstrittene Osterweiterung: Putin protestiert auf Nato-Gipfel - Russland fühlt sich „,direkt bedroht“. http://www.spiegel.de/politik/ausland/umstrittene-osterweiterungputin-protestiert-auf-nato-gipfel-russland-fuehlt-sich-direkt-bedroht-a-545451.html. Zugegriffen: 20. Sept. 2014.

Steinmeier, F. -W. (2013). Rede von Außenminister Frank-Walter Steinmeier bei der Amtsübergabe im Auswärtigen Amt am 17. Dezember 2013. http://www.auswaertiges-amt.de/DE/Infoservice/Presse/ Reden/2013/131217-BM Antrittsrede.html. Zugegriffen: 20. Sept. 2014.

tvn24. (2014, 31. August). Putin chce rozmów o „organizacji społeczeństwa i państwowości na południowym wschodzie Ukrainy“. http://www.tvn24.pl/wiadomosci-ze-swiata,2/putin-chce-rozmowo-organizacji-spoleczenstwa-i-panstwowosci-na-poludniowym-wschodzie-ukrainy,463613.html. Zugegriffen: 22. Okt. 2014.

Węsierski, L. (2014). Wspólna Dekada. Polska i Niemcy 10 lat razem w Unii Europejskiej. Agnieszka Łada (Hrsg.) ISP.

Wikipedia. Igor Strelkov. http://en.wikipedia.org/wiki/Igor_Strelkov_\%28officer\%29. Zugegriffen: 20. Sept. 2014.

Winkler, H. A. (2007). Dluga droga na Zachód. Wrocław: Wydawnictwo Uniwersytetu Wrocławskiego.

Winkler, H. A. (2014, 14. April). Die Spuren schrecken. Putins deutsche Verteidiger wissen nicht, in welcher Tradition sie stehen. Der Spiegel, 16.

wPolityce.pl. (2013, 21. Oktober). Rosjanie przyznają wprost: Obaliliśmy gabinet Kaczyńskiego. To embargo na polskie mięso doprowadziło do upadku rządu PiS. http://wpolityce.pl/polityka/169100rosjanie-przyznaja-wprost-obalilismy-gabinet-kaczynskiego-to-embargo-na-polskie-miesodoprowadzilo-do-upadku-rzadu-pis. Zugegriffen: 22. Okt. 2014.

Wprost 25. April 2005.

Zyrinowski, W. W. (2014). Władimir W. Żyrinowski zur Krim. https://www.youtube.com/ watch?v=RckBRN8pQ10. Zugegriffen: 22. Sept. 2014. 